\title{
Urban-rural disparities in treatment outcomes among recurrent TB cases in Southern Province, Zambia
}

Simon Mutembo ${ }^{1,2^{*}}$, Jane N. Mutanga ${ }^{1,2}$, Kebby Musokotwane ${ }^{2}$, Cuthbert Kanene ${ }^{3}$, Kevin Dobbin ${ }^{1}$, Xiaobai Yao ${ }^{1}$, Changwei $\mathrm{Li}^{1}$, Vincent C. Marconi ${ }^{4}$ and Christopher C. Whalen ${ }^{1}$

\begin{abstract}
Background: At least 13-20\% of all Tuberculosis (TB) cases are recurrent TB. Recurrent TB has critical public health importance because recurrent TB patients have high risk of Multi-Drug Resistant TB (MDR-TB). It is critical to understand variations in the prevalence and treatment outcomes of recurrent TB between different geographical settings.

The objective of our study was to estimate the prevalence of recurrent TB among TB cases and compare risk of unfavorable treatment outcomes between rural and urban settings.

Methods: In a retrospective cohort study conducted in southern province of Zambia, we used mixed effects logistic regression to asses associations between explanatory and outcome variables. Primary outcome was all-cause mortality and exposure was setting (rural/urban). Data was abstracted from the facility TB registers.

Results: Overall 3566 recurrent TB cases were diagnosed among 25,533 TB patients. The prevalence of recurrent TB was 15.3\% (95\% Cl: 14.8 15.9) in urban and 11.3\% (95\% Cl: 10.712 .0$)$ in rural areas. Death occurred in $197(5.5 \%)$, 103 (2.9\%) were lost to follow-up, and 113 (3.2\%) failed treatment. Rural settings had 70\% higher risk of death (adjusted OR: 1.7; 95\% Cl: 1.2 2.7). Risk of lost to follow-up was twice higher in rural than urban (adjusted OR: 2.0 95\% Cl: 1.3 3.0). Compared to HIV-uninfected, HIV-infected individuals on Antiretroviral Treatment (ART) were 70\% more likely to die (adjusted OR: 1.7; 95\% Cl: 1.2 3.1).

Conclusion: Recurrent TB prevalence was generally high in both urban and rural settings. The risk of mortality and lost to follow-up was higher among rural patients. We recommend a well-organized Directly Observed Therapy strategy adapted to setting where heightened TB control activities are focused on areas with poor treatment outcomes.
\end{abstract}

Keywords: Recurrent tuberculosis, Death, Treatment outcomes, Rural, Urban

\section{Background}

Tuberculosis (TB) remains a major problem in the world and a leading killer among infectious diseases [1]. In 2017 there were 10 million cases of TB and 1.6 million deaths among TB cases [1]. Multi-Drug Resistant TB (MDR-TB) poses a big threat to TB control because of the expensive and limited treatment options and high

\footnotetext{
* Correspondence: simon.mutembo@gmail.com

'Department of Epidemiology and Biostatistics, College of Public Health, University of Georgia, Athens, USA

${ }^{2}$ Ministry of Health, Provincial Health Office, Hospital Road, Livingstone, Zambia

Full list of author information is available at the end of the article
}

mortality. MDR-TB is common among patients with recurrent $\mathrm{TB}$, that is individuals who were previously treated with $\mathrm{TB}$ drugs for more than one month and once again have been diagnosed with TB disease [2].

It is estimated that $13 \%$ of all the TB cases reported to the World Health Organization (WHO) in 2017 were due to recurrent TB [1]. In high Human Immunodeficiency Virus (HIV) burden settings, TB recurrence rates are as high as $20 \%$ following standard TB treatment $[3$, 4]. Recurrent TB can result from reactivation of the original Mycobacterium tuberculosis or from re-infection with a different strain [5].

(c) The Author(s). 2019 Open Access This article is distributed under the terms of the Creative Commons Attribution 4.0 International License (http://creativecommons.org/licenses/by/4.0/), which permits unrestricted use, distribution, and reproduction in any medium, provided you give appropriate credit to the original author(s) and the source, provide a link to the Creative Commons license, and indicate if changes were made. The Creative Commons Public Domain Dedication waiver (http://creativecommons.org/publicdomain/zero/1.0/) applies to the data made available in this article, unless otherwise stated. 
Zambia is a country with a high prevalence of TB (455 cases per 100,000 population) and high prevalence of HIV infection (12\% among adults between 15 and 59 years) $[6,7]$. The extent of recurrent $\mathrm{TB}$ and treatment outcomes of recurrent TB cases have not been fully described. It is important to make distinctions between new and recurrent cases as well as the subgroups of recurrent cases because they are essential for monitoring the TB epidemic and TB program performance [8]. Knowing the prevalence, incidence and treatment outcomes of recurrent TB is important because recurrent $\mathrm{TB}$ patients have a high risk of multidrug resistant $\mathrm{TB}$ which requires prolonged treatment with more toxic drugs and is associated with higher rates of mortality [9]. To help TB program managers and other scientists involved in TB control to focus strategic activities for recurrent $\mathrm{TB}$ detection, treatment and consequently prevent MDR-TB, the scientific world must understand the variations in recurrent $\mathrm{TB}$ treatment outcomes between different subpopulations and geographical settings.

The burden of $\mathrm{TB}$ disease is generally considered to be higher in urban settings than rural settings due to overcrowding, high HIV prevalence and occupational transmission [6]. However it is not known whether a difference exists between the prevalence of recurrent TB in rural and urban settings. It is critical to understand the difference in the prevalence of recurrent TB between rural and urban settings because of the differences in the social and economic standards as well as differences in the accessibility and quality of health care between the 2 settings. Health care service delivery is better in urban populations because health facilities are easy to reach whereas rural patients must travel long distances [10, 11]. Additionally, urban settings have more skilled health care providers with more clinical experience in the management of TB and HIV and access to better diagnostics. In contrast, most TB patients in urban settings are from deprived communities and social disadvantages such as slums which may contribute to poorer TB treatment outcomes [10].

We examined the prevalence of recurrent $\mathrm{TB}$ among TB cases notified to the National TB Program (NTP) in southern province of Zambia. We assessed for risk factors associated with death, loss to follow up and failure among recurrent TB patients accessing treatment at health facilities in rural and urban settings.

\section{Methods}

\section{Study design}

A retrospective cohort study was conducted by analyzing data collected in the NTP in southern province of Zambia.

\section{Study setting and population}

The study was conducted in a predominantly rural setting $(85 \%)$ with a high TB case notification rate $(>300$ cases per 100,000 population per year) [12].

All adults and children who were treated for recurrent TB between January 2006 and June 2014 were included in the analysis. Recurrent TB was defined as a case of TB disease diagnosed in a patient who had been treated before for more than 1 month with TB drugs [2].

\section{Study exposure}

The study assessed factors associated with death, treatment failure and loss to follow up (LTFU) among patients treated for recurrent TB. The main exposure was health facility location classified as either rural or urban. The definition of rural or urban was based on the Ministry of health and Central Statistical Office of Zambia classification of health facilities [11]. A rural area is a location where the source of livelihood for at least $75 \%$ of the population is agriculture and agriculture allied activities and the health facility in the area serve a catchment population of less than 30,000 [11]. Urban health facilities are facilities that are located in urban settings and serve catchment populations of over 30,000 [11].

\section{Study outcomes}

The primary outcome was all-cause mortality which is death from TB disease or any other cause before the patient successfully completed treatment. Death was verified by the attending physician through death certificate or verbal report from treatment supporters or the patient's next of kin.

The secondary outcomes were LTFU and treatment failure. LTFU was defined as a patient having missed more than two months of consecutive doses [2]. Treatment failure was defined as patient being smear positive after more than 5 months of treatment [2].

\section{Covariates}

The following clinical and demographic characteristics were evaluated as risk factors for death: age, sex, HIV status and ART in TB/HIV co-infected patients, treatment delay and clinical classification of disease. Clinical Pulmonary $\mathrm{TB}$ was a situation where the attending clinician made a diagnosis of pulmonary $\mathrm{TB}$ and decided to give the patient a full course of anti-TB treatment without bacteriological confirmation; Bacteriologically confirmed TB was when the diagnosis and treatment was supported by biological specimen such as by AcidAlcohol Fast Bacilli (AAFB) smear microscopy, culture or GeneXpert [2]. 


\section{Data collection and data integrity}

We abstracted clinical and demographic data on the TB cases that had been recorded in the NTP register at every outpatient visit. Data entries were subjected to quality control, including removal of duplicate data entries, outliers in continuous variables, date parameters and ambiguous or erroneous entries in categorical entries. Verification of extracted records with source data was done in a randomly selected subset of 10 patients for every 100 entries from each site. After quality control, all available records for TB patients registered at the participating health centers between January 2006 and January 2013 were screened for inclusion.

\section{Statistical analysis}

Data were described using frequency counts and percentages for categorical variables, means and standard deviations for normally distributed continuous variables. In the primary analysis we estimated the odds ratio and the 95\% confidence intervals for death among rural cases compared with urban cases. We first estimated the crude odds ratio and then stratified to assess for confounding and interaction. For associations between explanatory variables and the primary and secondary outcomes we used mixed effects logistic regression since participant data was organized at more than one level: district, health facility and rural/ urban setting. The data were cleaned and analyzed using Stata v.14.

\section{Ethical considerations}

Ethical approval was obtained from the Macha Research Trust ethics committee, the University of Georgia institutional review board and regulatory authority from the Zambia National Health Research Authority. Before commencing data abstraction administrative permission was obtained from the provincial health office in southern province.

\section{Results}

\section{Case enrollment}

Data from 25,533 TB patients was abstracted and after excluding new $\mathrm{TB}$ cases and patients who transferred out, we analyzed 3555 recurrent TB cases. Of these recurrent TB cases $990(27.8 \%)$ were in rural areas and $2565(72.2 \%)$ were in urban areas (Fig. 1).

\section{Prevalence of recurrence among TB cases}

The overall prevalence of recurrent TB before excluding cases that transferred out was 14\% (95\% CI; 13.5 14.4). In urban setting the prevalence was $15.3 \%$ (95\% CI: 14.8 $15.9)$ and $11.3 \%$ (95\% CI: 10.7 12.0) in rural areas
(Table 1). TB recurrence in HIV negative TB cases was 10.0\% $(n=499 ; 95 \%$ CI: 9.210 .9$)$ and $16.1 \%(n=2216$; 95\% CI: 15.5 16.7) in HIV seropositive positive recurrent TB cases. In men prevalence of recurrent TB was 13\% $(n=1506 ; 95 \%$ CI: 12.413 .6$)$ and $14.9 \%(n=2049 ; 95 \%$ CI: 14.3 15.5) in women.

\section{Demographic and clinical characteristics}

The mean was 36.3 years (Standard deviation $(\mathrm{SD})=14.8$ ) and most of the recurrent TB cases were male $(n=2019$; $56.9 \%)$ Of the total cases $2745(77 \%)$ were recurrent cases due to relapse, $31(0.9 \%)$ were recurrence after LTFU, 29 $(0.8 \%)$ were recurrence after failure and $106(3.0 \%)$ were classified as others (Table 2).

Of all the HIV seropositive cases of recurrent TB that were analyzed $1712(78.8 \%)$ cases were in urban areas whereas 461 (21.2\%) were in rural areas (Table 2). Most patients received treatment within the first 14 days of registering in the TB clinic $(n=3135 ; 88.2 \%)$.

\section{Treatment outcomes}

Of the 3555 patients who were included in the analysis 265 (7.5\%) were cured and 2877 (80.9\%) completed treatment (Table 3). In the urban areas 111 (4.3\%) cases died, 95 (3.7\%) cases experienced treatment failure and $52(2.0 \%)$ were LTFU. In the rural areas 51 (5.2\%) died, 18 (1.8\%) experienced $\mathrm{TB}$ treatment failure and 51 (5.2\%) were LTFU.

\section{Univariable and multivariable analysis results}

In both the univariable and multivariable analysis place of TB treatment was statistically associated with allcause mortality (Table 4). After adjusting for sex, age group, microbiological confirmation, and HIV status, recurrent TB cases treated in the rural settings were $70 \%$ more likely to die while on TB treatment. (aOR: 1.7, 95\% CI: 1.2 2.7). HIV positive patients on ART were $70 \%$ more likely to die when compared to HIV negative patients (aOR 1.7; 95\% CI: 1.4-3.7).

For secondary outcomes of LTFU and TB treatment failure analyzed separately rural areas had worse $\mathrm{TB}$ treatment outcomes. After adjusting for calendar year of treatment, HIV and ART status recurrent TB patients in the rural areas where twice more likely to be LTFU as compare to those in urban areas (aOR 2.0, 95\% CI: 1.3 3.0) (Table 5). For recurrent TB treatment failure, patients in rural areas were $70 \%$ more likely to experience treatment failure (aOR 1.7, 95\% CI: 0.7 5.1) (Table 6).

\section{Discussion}

In this retrospective cohort of $\mathrm{TB}$ patients, the overall prevalence of recurrent TB of $14 \%$ is high and similar to 


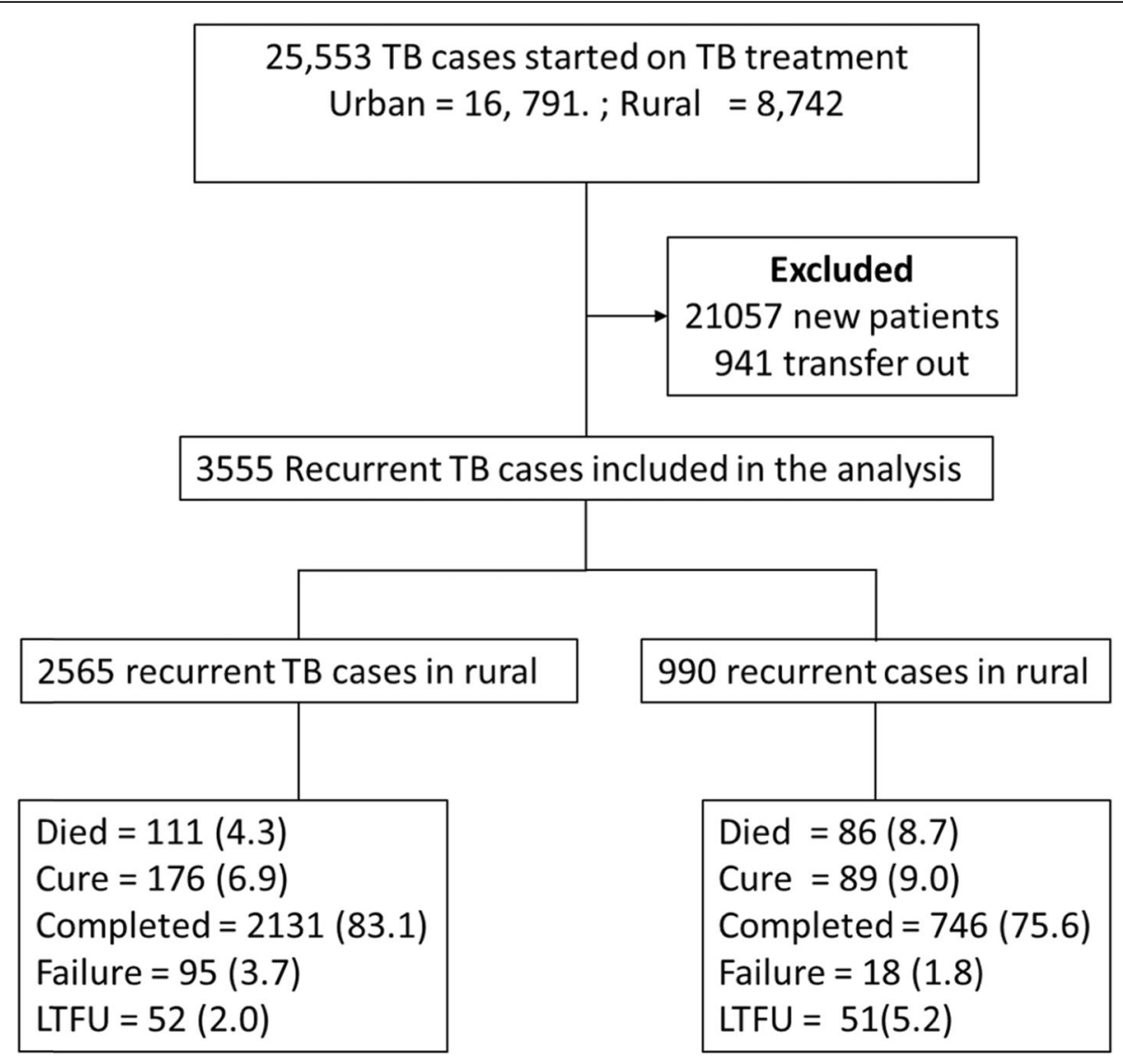

Fig. 1 Consort diagram showing the selection of recurrent TB patients and treatment outcomes in rural and urban setting

Table 1 Prevalence of Tuberculosis retreatment cases by different characteristics among patients who were treated for tuberculosis

\begin{tabular}{llll}
\hline $\begin{array}{l}\text { Patient } \\
\text { characteristics }\end{array}$ & $\begin{array}{l}\text { total number } \\
\text { of TB cases }\end{array}$ & $\begin{array}{l}\text { recurrent } \\
\text { cases }\end{array}$ & $\begin{array}{l}\text { Prevalence } \\
\text { in \% }(95 \% \text { Cl) }\end{array}$ \\
\hline $\begin{array}{l}\text { Overall } \\
\text { Urban site }\end{array}$ & 25,533 & 3566 & $14.0(13.514 .4)$ \\
$\quad 16,791$ & 2574 & $15.3(14.815 .9)$ \\
$\begin{array}{l}\text { Rural site } \\
\text { Age }\end{array}$ & 8742 & 992 & $11.3(10.712 .0)$ \\
10 \& below & 3259 & & \\
$11-18$ & 2641 & 280 & $8.6(7.79 .6)$ \\
$19-55$ & 16,835 & 272 & $10.3(9.111 .5)$ \\
56 \&older & 2769 & 2614 & $15.5(1516.1)$ \\
Sex & & 400 & $14.5(13.115 .8)$ \\
Female & 11,569 & 1506 & $13(12.413 .6)$ \\
Male & 13,726 & 2049 & $14.9(14.315 .5)$
\end{tabular}

HIV status

$\begin{array}{llll}\text { negative } & 11,709 & 1382 & 11.8(9.210 .9) \\ \text { positive } & 13,795 & 2216 & 16.1(15.516 .7)\end{array}$

Note: In this table we estimate the prevalence using the overall number of cases before excluding cases who did not have the outcomes of interest at the end of follow (patients who transferred out and the TB treatment outcome was not documented other sub-Saharan Africa countries [15]. It is higher in urban (15.3\%) than in rural areas (11.3\%). Recurrent TB prevalence was higher among HIV seropositive individuals than HIV seronegative individuals (16.1 vs 11.8 ). Recurrent TB cases receiving treatment in rural areas were $70 \%$ more likely to die when compared to patients treated in urban areas. The risk LTFU was twice higher in rural areas than urban areas.

Overall the prevalence of recurrent TB was high and similar to other sub-Saharan African settings with high HIV prevalence [3]. The prevalence was slightly higher in urban areas than rural areas. High prevalence of recurrent TB can be driven by either a high rate of exogenous re-infection or high rate of relapse of the initial $M$. tuberculosis infection. In this study, high prevalence of $\mathrm{TB}$ in the general population and among HIV seropositive individuals provides a suitable environment for high exposure to $M$. tuberculosis and consequently a high potential of re-infection. Because of the limited laboratory capacity, distinction between exogenous reinfection and true relapse cases could not be made. However, previous molecular studies in similar settings 
Table 2 Clinical and demographic characteristics of recurrent TB cases treated for drug susceptible TB in Zambia, southern province

\begin{tabular}{|c|c|c|c|c|}
\hline Characteristic & Level & Total & Urban areas & Rural areas \\
\hline & & $n$ (percent) & $n$ (percent) & $n$ (percent) \\
\hline \multirow[t]{3}{*}{ Sex } & Female & $1482(41.7)$ & $1045(40.7)$ & $437(44.1)$ \\
\hline & male & $2019(56.9)$ & $1473(57.4)$ & $546(55.2)$ \\
\hline & Missing & $54(1.52)$ & $47(1.8)$ & $7(0.7)$ \\
\hline \multirow[t]{5}{*}{ Age group ${ }^{a}$} & $10 \&$ below & $128(3.6)$ & $93(3.6)$ & $35(3.5)$ \\
\hline & $11-18$ & $140(3.9)$ & $103(4.0)$ & $37(3.7)$ \\
\hline & $19-55$ & $2185(79.2)$ & $2064(80.5)$ & $751(75.9)$ \\
\hline & 56 \& older & $403(11.3)$ & $259(10.1)$ & $144(14.6)$ \\
\hline & Missing & $69(1.9)$ & $46(1.8)$ & $23(2.3)$ \\
\hline \multirow[t]{2}{*}{ Microbiological confirmation } & clinical & $2519(70.9)$ & $1874(73.1)$ & $639(64.6)$ \\
\hline & confirmed & $1036(29.1)$ & $689(26.9)$ & $347(35.1)$ \\
\hline \multirow[t]{5}{*}{ Reason for retreatment } & Relapse patients & $2745(77.2)$ & $2126(82.9)$ & $619(62.5)$ \\
\hline & Other & $644(18.1)$ & $330(12.9)$ & $314(31.7)$ \\
\hline & Treatment after LTFU patients & $31(0.8)$ & $28(1.1)$ & $3(0.3)$ \\
\hline & Treatment after failure patients & $29(0.82)$ & $15(0.6)$ & $14(1.4)$ \\
\hline & Missing & $106(3.0)$ & $66(2.6)$ & $40(4.0)$ \\
\hline \multirow[t]{3}{*}{ Site of disease } & Pulmonary & 2937 (82.6) & 2086 (81.3) & $851(86.0)$ \\
\hline & Extra-pulmonary & $537(15.1)$ & $418(16.3)$ & $119(12.0)$ \\
\hline & Missing & $81(2.3)$ & $61(2.4)$ & $20(2.0)$ \\
\hline \multirow[t]{2}{*}{ Treatment Delay } & 14 days \& less & 3135 (88.2) & $2286(89.1)$ & $849(85.8)$ \\
\hline & 15 days and more & $420(11.8)$ & $279(10.9)$ & $141(14.2)$ \\
\hline \multirow[t]{2}{*}{ Calendar year } & $<2010$ & $1884(53)$ & $1336(52.1)$ & $548(55.4)$ \\
\hline & 2010 \& after & $1671(47)$ & $1229(47.9)$ & $442(44.7)$ \\
\hline \multirow[t]{2}{*}{ Facility type } & Hospital & $1353(38.1)$ & $926(36.1)$ & $427(43.1)$ \\
\hline & Health Center or clinic & $2202(61.9)$ & 1639 (63.9) & $563(56.9)$ \\
\hline \multirow[t]{2}{*}{ HIV status } & Negative & $1382(38.9)$ & $853(61.7)$ & $529(38.3)$ \\
\hline & Positive & $2173(61.1)$ & $1712(78.8)$ & 461 (21.2) \\
\hline
\end{tabular}

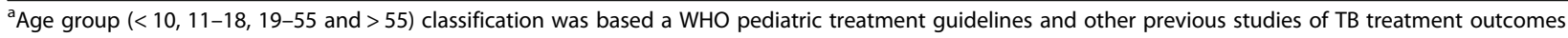
$[13,14]$.

have demonstrated that a large proportion of recurrent TB cases among HIV patients are caused by exogenous reinfection. In a cohort of South African gold-mine workers, HIV-1 infection was strongly associated with re-infection but not with relapse. This finding has

Table 3 TB treatment outcomes among recurrent TB cases in rural and urban settings in southern province, Zambia

\begin{tabular}{llll}
\hline $\begin{array}{l}\text { Treatment } \\
\text { outcomes }\end{array}$ & $\begin{array}{l}\text { Total } \\
\text { number } \\
\text { (percent) }\end{array}$ & $\begin{array}{l}\text { Urban } \\
\mathrm{n} \text { (percent) }\end{array}$ & $\begin{array}{l}\text { Rural } \\
\mathrm{n} \text { (percent) }\end{array}$ \\
\hline Cure & $265(7.5)$ & $176(6.9)$ & $89(9.0)$ \\
Completed & $2877(80.9)$ & $2131(83.1)$ & $746(75.4)$ \\
Failure & $113(5.5)$ & $95(3.7)$ & $18(1.8)$ \\
Died & $197(2.9)$ & $111(4.3)$ & $86(8.7)$ \\
LTFU & $103(3.2)$ & $52(2.0)$ & $51(5.2)$ \\
Total & 3555 & 2565 & 990 \\
\hline
\end{tabular}

programmatic and public health consequences because even with effective TB treatment regimens TB recurrence can be more common in population with high HIV prevalence as long as exposure to $M$. tuberculosis is high $[3,16]$.. Another study in Uganda showed that recurrent TB occurring more than 2 years after completing TB treatment was mainly due to re-infection whereas recurrence occurring within 2 years of treatment was due to relapse. Unfortunately, the NTP registers do not capture the dates when the last TB treatment was completed and hence it was not possible to ascertain the time interval between TB episodes [15].

The risk of death was higher in rural areas than urban areas. Generally, patients in rural areas have worse TB treatment outcomes than patients in the urban areas including LTFU $[10,17]$. Our study presents data on recurrent TB and provides a valid assessment of recurrent TB treatment outcomes presented separately for death, 
Table 4 Estimates of the risk of death (OR) in recurrent TB patients in southern province Zambia according to demographic and clinical characteristics

\begin{tabular}{|c|c|c|c|c|}
\hline \multirow[t]{2}{*}{ Characteristics } & Total & Died & Crude & Adjusted \\
\hline & & & OR (95\% Cl) & OR (95\% Cl) \\
\hline
\end{tabular}

\begin{tabular}{lllll}
\hline Location & & & & \\
Urban & 2574 & 111 & 1 & 1 \\
Rural & 991 & 86 & $2.1(1.52 .8)$ & $1.7(1.22 .7)$ \\
Sex & & & & \\
Female & 1482 & 112 & 1 & 1 \\
Male & 2019 & 85 & $0.5(0.40 .7)$ & $0.6(0.41 .0)$
\end{tabular}

Age group

$\begin{array}{llll}\text { Below 55 } & 2721 & 171 & 1 \\ >55 & 403 & 26 & 1.0(0.81 .3)\end{array}$

Microbiological confirmation

$\begin{array}{llllll}\text { clinical } & 2519 & 62 & 1 & \\ \text { confirmed } & 1036 & 135 & 1.1(0.81 .5) & 0.6(0.41 .0)\end{array}$

Site of disease

\begin{tabular}{|c|c|c|c|c|}
\hline pulmonary & 2937 & 169 & 1 & \\
\hline Extra-pulmonary & 537 & 24 & $0.8\left(\begin{array}{ll}0.5 & 1.2\end{array}\right)$ & \\
\hline \multicolumn{5}{|l|}{ Treatment Delay } \\
\hline$<=14$ days & 3135 & 174 & 1 & \\
\hline$>15$ days & 420 & 23 & $1.2\left(\begin{array}{l}0.6 \\
1.5\end{array}\right)$ & \\
\hline \multicolumn{5}{|l|}{ Facility type } \\
\hline \multicolumn{5}{|l|}{ Calendar } \\
\hline$<=2010$ & 1884 & 106 & 1 & \\
\hline$>2010$ & 1671 & 91 & $0.9\left(\begin{array}{ll}0.7 & 1.3)\end{array}\right.$ & \\
\hline \multicolumn{5}{|l|}{ HIV } \\
\hline Seronegative & 1382 & 367 & 1 & \\
\hline Seropositive + ART & 1187 & 610 & $1.6(1.43 .7)$ & $1.7(1.43 .7)$ \\
\hline Seropositive no ART & 986 & 114 & $2.3(1.86 .8)$ & $2.3(1.66 .0)$ \\
\hline
\end{tabular}

treatment failure and LTFU. For recurrent TB patients understating the magnitude of LTFU is critical because recurrent TB patients who are LTFU are likely to progress to MDR-TB and are a potential risk to further transmission of the multi-drug resistant $M$. tuberculosis. Although the prevalence of recurrent TB was lower in rural than urban settings, LTFU was higher in rural settings. This implies that rural settings are at increased risk of creating next generation of MDR-TB cases.

Most studies that have assessed risk factors associated with unfavorable $\mathrm{TB}$ treatment outcomes found that urban areas generally have better outcomes because of better organized patient follow up systems and relatively easy access to health care services [18-20]. A qualitative study conducted in Uganda highlighted geographical
Table 5 Estimates of the risk of LTFU (OR) in recurrent TB patients in southern province Zambia according to demographic and clinical characteristics

\begin{tabular}{|c|c|c|c|c|}
\hline Characteristic & total & LTFU & $\begin{array}{l}\text { Crude OR } \\
(95 \% \mathrm{Cl})\end{array}$ & $\begin{array}{l}\text { Adjusted OR } \\
(95 \% \mathrm{Cl})\end{array}$ \\
\hline \multicolumn{5}{|l|}{ Setting } \\
\hline Urban & 2565 & 52 & 1.0 & \\
\hline Rural & 990 & 51 & $1.9(1.13 .4)$ & $2.0(1.33 .0)$ \\
\hline \multicolumn{5}{|l|}{ Sex } \\
\hline Male & 2019 & 53 & 1.0 & \\
\hline Female & 1482 & 50 & $0.8\left(\begin{array}{lll}0.5 & 1.2\end{array}\right)$ & \\
\hline \multicolumn{5}{|l|}{ Age group } \\
\hline Below 55 & 2721 & 90 & 1.0 & \\
\hline Above 55 & 403 & 13 & $0.9(0.812)$ & \\
\hline \multicolumn{5}{|l|}{ Calendar year } \\
\hline Before 2010 & 1884 & 53 & 1.0 & \\
\hline After 2010 & 1671 & 50 & $0.99(0.71 .5)$ & $1.1(0.71 .5)$ \\
\hline \multicolumn{5}{|l|}{ Treatment delay } \\
\hline Less than 14 days & 3135 & 92 & 1.0 & \\
\hline 14 days and more & 420 & 11 & $0.8(0.41 .4)$ & \\
\hline \multicolumn{5}{|l|}{ Classification of TB } \\
\hline Microbiology confirmed & 1036 & 40 & 1.0 & \\
\hline clinical & 2460 & 63 & & \\
\hline \multicolumn{5}{|l|}{ HIV and ART status } \\
\hline HIV negative & 1382 & 57 & 1.0 & \\
\hline HIV seropositive on ART & 1187 & 39 & $0.9(0.61 .3)$ & $0.8(0.51 .2)$ \\
\hline HIV seropositive no ART & 986 & 7 & $0.9(0.7$ 1.4) & $0.9\left(\begin{array}{ll}0.8 & 1.4\end{array}\right)$ \\
\hline
\end{tabular}

barriers in rural areas as one of the barriers for delivery of routine TB diagnostic and treatment services [19]. Interviews highlighted physical remoteness of their homes from the clinic and the tough terrain encountered during travel as the principal barrier to accessing timely TB evaluation and treatment [19]. Challenges in accessing diagnostic and treatment services have potential of influencing TB treatment outcomes and increasing mortality among TB patients. Additionally, urban settings have a high prevalence of TB and HIV and have more healthcare providers as compared to rural settings [11]. Therefore health workers in the urban areas have more clinical experience in managing TB and HIV.

The strength of this study is that it describes recurrent TB cases from a large cohort of TB cases at multiple rural and urban sites in a setting with high prevalence of both TB and HIV. Additionally, the paper highlight some of the gaps in the program and clinical case management of recurrent TB. The gaps herein highlighted are likely to be found in most NTPs in sub-Saharan Africa. 
Table 6 Estimates of the risk of treatment failure (OR) in recurrent TB patients in southern province Zambia according to demographic and clinical characteristics

\begin{tabular}{|c|c|c|c|c|}
\hline Characteristic & total & $\begin{array}{l}\text { Treatment } \\
\text { failure }\end{array}$ & $\begin{array}{l}\text { Crude OR } \\
(95 \% \mathrm{Cl}) \\
\end{array}$ & $\begin{array}{l}\text { Adjusted OR } \\
(95 \% \mathrm{Cl})\end{array}$ \\
\hline \multicolumn{5}{|l|}{ Setting } \\
\hline Urban & 2565 & 95 & 1.0 & \\
\hline Rural & 990 & 18 & $1.4(0.53 .9)$ & $1.7(0.75 .1)$ \\
\hline \multicolumn{5}{|l|}{ Sex } \\
\hline Male & 2019 & 60 & & \\
\hline Female & 1482 & 50 & $0.8(0.51 .2)$ & \\
\hline \multicolumn{5}{|l|}{ Age group } \\
\hline Below 18 years & 268 & 10 & 1.0 & \\
\hline $18-55$ & 2815 & 86 & $0.7(0.41 .5)$ & \\
\hline Above 55 & 403 & 17 & $1.3(0.52 .9)$ & \\
\hline \multicolumn{5}{|l|}{ Calendar year } \\
\hline Before 2010 & 1884 & 54 & 1.0 & \\
\hline After 2010 & 1671 & 59 & $1.2\left(\begin{array}{ll}0.8 & 1.8\end{array}\right)$ & \\
\hline \multicolumn{5}{|l|}{ Treatment delay } \\
\hline Less than 14 days & 3135 & 90 & & \\
\hline 14 days and more & 420 & 23 & $2.1(1.23 .4)$ & $1.7(0.92 .4)$ \\
\hline \multicolumn{5}{|l|}{ Classification of TB } \\
\hline Microbiology confirmed & 1036 & 63 & & \\
\hline clinical & 2460 & 50 & $0.3(0.20 .4)$ & $0.4(0.20 .6)$ \\
\hline \multicolumn{5}{|l|}{ HIV and ART status } \\
\hline HIV negative & 1382 & 45 & 1.0 & \\
\hline HIV seropositive on ART & 1187 & 27 & $0.7(0.51 .4)$ & $0.7(0.41 .2)$ \\
\hline HIV seropositive no ART & 986 & 41 & $0.8(0.41 .2)$ & $1.0\left(\begin{array}{ll}0.6 & 1.7)\end{array}\right.$ \\
\hline
\end{tabular}

\section{Limitations}

As in any real-world data or observational studies our analysis was subject to some limitations. An obvious weakness of this analysis was errors in the recorded data and missing which could not be validated. To address this potential selection bias, we conducted a sensitivity analysis by comparing baseline characteristics of those included in the analysis and those excluded. The two sample populations were similar on most aspects. Hence selection bias was very unlikely. The data used in this analysis program data meant for clinical care and follow up of patients. It does not capture a lot of social and demographic factors. Therefore, risk factors associated with the prevalence of recurrent $\mathrm{TB}$ could not be determined.

\section{Public health relevance}

We have shown that recurrent rates of $\mathrm{TB}$ are high in both rural and urban settings with rural areas having worse treatment outcomes as compared to urban areas. Therefore, a well-organized patient monitoring system such as effectively administered Directly Observed Treatment Short course (DOTS) can help early detection of recurrent cases and reduce mortality and LTFU. DOTS must be adapted to the setting.

\section{Conclusion}

Prevalence of recurrent TB was high in both rural and urban areas in the southern part of Zambia. The prevalence was higher among TB patients who access treatment at health facilities in urban areas than rural areas. However, TB recurrent cases accessing treatment in rural areas experienced higher mortality and worse treatment outcomes as compare to those accessing treatment in urban areas. We strongly recommend effective DOTS adapted to the setting where heightened DOTS activities are focused in areas or communities with poor TB treatment outcomes.

\section{Abbreviations \\ AAFB: Acid-alcohol fast bacilli; aOR: Adjusted odds ratio; ART: Anti-retroviral therapy; Cl: Confidence interval; DOTS: Directly observed treatment short course; HIV: Human immunodeficiency virus; LTFU: Lost to follow up; MDR: Multi drug resistant; NTP: National tuberculosis control program; OR: Odds ratio; SD: Standard deviation; WHO: World Health Organization}

\section{Acknowledgements}

The epidemiology in action research group at the University of Georgia for the critical input into the analytic methods of this manuscript. We are grateful to the provincial medical office in southern province of Zambia for providing the resources to perform this study. We are thankful to Mr. Boyd Mwangelwa, Mr. Johanzi Mvula and Mr. Francis Chibinga for the active role in data collection and processing.

\section{Authors' contributions}

SM (study concept and data analysis). SM, JNM, CCW, KM, CK (study design, development of data collection tools, data interpretation, manuscript writing and manuscript review). SM, JNM, CCW, KM, CK, VCM, KD, CL, XY (study implementation, data collection, data cleaning, manuscript writing and critical revision the manuscript). SM, CCW, VCM, KD, CL, XY, JNM (critical revision of data analysis and interpretation). All the authors read and approved the manuscript for publication.

\section{Funding}

This study was supported in part by the monitoring and evaluation unit of the provincial health office in southern province Zambia and by grants from the National Institutes of Allergy and Infectious Disease (Al093856). The funding source were not involved in the design, collection, analysis and interpretation of the data nor in the writing of the manuscript. The content of this paper is solely the responsibility of the authors and does not represent the official views of the funders.

\section{Availability of data and materials}

The data that support the findings of this study are available from the national TB control program at the provincial health office in southern province Zambia, but restrictions apply to the availability of these data, which were used under license for the current study and are currently not publicly available. Data can be made available for other authors upon request and with the permission and approval of the Ministry of Health and the Zambia National Research Authority.

\section{Ethics approval and consent to participate}

This study was approved by the Zambia National Health Research Authority and the institutional review boards at Macha Research Trust and the University of Georgia. We conducted analysis of anonymized routinely collected program data, hence all the institutional review boards waived 
informed consent. Administrative permission was obtained from the Ministry of Health provincial health office to before starting the data abstraction.

\section{Consent for publication}

Not applicable.

\section{Competing interests}

The authors declare that they have no competing interests.

\section{Author details}

'Department of Epidemiology and Biostatistics, College of Public Health, University of Georgia, Athens, USA. ${ }^{2}$ Ministry of Health, Provincial Health Office, Hospital Road, Livingstone, Zambia. ${ }^{3}$ Centers for Disease Control and Prevention, Zambia Country Office, Livingstone, Zambia. ${ }^{4}$ Division of Infectious Diseases, School of Medicine, Emory University, Atlanta, USA.

Received: 13 July 2019 Accepted: 17 December 2019

Published online: 30 December 2019

\section{References}

1. World Health Organization. Global tuberculosis report 2018. 2019. Available from: https://www.who.int/tb/publications/global_report/en/.

2. World Health Organization. Definitions and reporting framework for tuberculosis - 2013 revision. 2014. Available from: http://apps.who.int/iris/ bitstream/10665/79199/1/9789241505345_eng.pdf?ua=1.

3. Sonnenberg P, Murray J, Glynn JR, Shearer S, Kambashi B, Godfrey-Faussett P. HIV-1 and recurrence, relapse, and reinfection of tuberculosis after cure: a cohort study in South African mineworkers. Lancet. 2001:358(9294):1687-93.

4. Panjabi R, Comstock G, Golub J. Recurrent tuberculosis and its risk factors: adequately treated patients are still at high risk. Int J Tuberc Lung Dis. 2007; 11(8):828-37.

5. Van Rie A, Warren R, Richardson M, Victor TC, Gie RP, Enarson DA, et al. Exogenous reinfection as a cause of recurrent tuberculosis after curative treatment. N Engl J Med. 1999;341(16):1174-9.

6. Kapata N, Chanda-Kapata P, Ngosa W, Metitiri M, Klinkenberg E, Kalisvaart N, et al. The prevalence of tuberculosis in Zambia: results from the first national TB prevalence survey, 2013-2014. PLoS One. 2016:11(1):e0146392.

7. Ministry of Health. Zambia population-based HIV impact assesment-20152016:Preliminary report. 2016. Available from: https://phia.icap.columbia.edu/ wp-content/uploads/2017/11/FINAL-ZAMPHIA-First-Report_11.30.17_CK.pdf.

8. World Health Organization. Guidelines for treatment of tuberculosis. 2010 [fourth:[Available from: http://www.who.int/tb/publications/2010/ 9789241547833/en/.

9. O'Donnell MR, Padayatchi N, Kvasnovsky C, Werner L, Master I, Horsburgh CR Jr. Treatment outcomes for extensively drug-resistant tuberculosis and HIV co-infection. Emerg Infect Dis. 2013;19(3):416-24.

10. Abubakar I, Crofts J, Gelb D, Story A, Andrews N, Watson J. Investigating urban-rural disparities in tuberculosis treatment outcome in England and Wales. Epidemiol Infect. 2008;136(1):122-7.

11. Ministry of Health. 2012 List of Health Facilities in Zambia. 2013.

12. Ministry of Health. Southern Province: 2015 Tuberculosis and leprosy control progress report. 2016.

13. World Health Organization. Rapid advise - treatment of tuberculosis in children 2010. Available from: http://apps.who.int/iris/bitstream/1 0665/44444/1/9789241500449 eng.pdf.

14. Ncube R, Takarinda K, Zishiri C, van den Boogaard W, Mlilo N, Chiteve $C$, et al. Age-stratified tuberculosis treatment outcomes in Zimbabwe: are we paying attention to the most vulnerable? Public Health Action. 2017;7(3):212-7.

15. Luzze H, Johnson DF, Dickman K, Mayanja-Kizza H, Okwera A, Eisenach $K$, et al. Relapse more common than reinfection in recurrent tuberculosis 1-2 years post treatment in urban Uganda. Int J Tuberc Lung Dis. 2013;17(3):361-7.

16. Fitzpatrick L, Okwera A, Mugerwa R, Ridzon R, Ellner J, Onorato I. An investigation of suspected exogenous reinfection in tuberculosis patients in Kampala, Uganda. Int J Tuberc Lung Dis. 2002;6(6):550-2.

17. Musaazi J, Kiragga A, Castelnuovo B, Kambugu A, Bradley J, Rehman A. Tuberculosis treatment success among rural and urban Ugandans living with HIV: a retrospective study. Public Health Action. 2017;7(2):100-9.

18. Adatu F, Odeke R, Mugenyi M, Gargioni G, McCray E, Schneider E, et al. Implementation of the DOTS strategy for tuberculosis control in rural
Kiboga District, Uganda, offering patients the option of treatment supervision in the community, 1998-1999. Int J Tuberc Lung Dis. 2003; 7(9):S63-71

19. Cattamanchi A, Miller CR, Tapley A, Haguma P, Ochom E, Ackerman S, et al. Health worker perspectives on barriers to delivery of routine tuberculosis diagnostic evaluation services in Uganda: a qualitative study to guide clinicbased interventions. BMC Health Serv Res. 2015;15(1):10.

20. Nuwaha F. Factors influencing completion of treatment among tuberculosis patients in Mbarara District, Uganda. East Afr Med J. 1997;74(11):690-3.

\section{Publisher's Note}

Springer Nature remains neutral with regard to jurisdictional claims in published maps and institutional affiliations.
Ready to submit your research? Choose BMC and benefit from:

- fast, convenient online submission

- thorough peer review by experienced researchers in your field

- rapid publication on acceptance

- support for research data, including large and complex data types

- gold Open Access which fosters wider collaboration and increased citations

- maximum visibility for your research: over $100 \mathrm{M}$ website views per year

At $\mathrm{BMC}$, research is always in progress.

Learn more biomedcentral.com/submissions 